TITLE:

\title{
Electrical properties of Cul films prepared by spin coating
}

$\operatorname{AUTHOR}(\mathrm{S})$ :

Inudo, Shota; Miyake, Masao; Hirato, Tetsuji

\section{CITATION:}

Inudo, Shota ... [et al]. Electrical properties of Cul films prepared by spin coating. Physica Status Solidi (A) Applications and Materials Science 2013, 210(11): 2395-2398

\section{ISSUE DATE:}

2013-11

URL:

http://hdl.handle.net/2433/237674

\section{RIGHT:}

This is the peer reviewed version of the following article: [Physica Status Solidi (A), Volume210, Issue11, November 2013, Pages 2395-2398], which has been published in final form at https://doi.org/10.1002/pssa.201329319. This article may be used for non-commercial purposes in accordance with Wiley Terms and Conditions for Use of Self-Archived Versions.; The full-text file will be made open to the public on 20 November 2014 in accordance with publisher's 'Terms and Conditions for Self-Archiving': この論文は出版社版でありません。引用の際には出版社版をご確認ご利用ください 。; This is not the published version. Please cite only the published version. 


\title{
Electrical properties of Cul films prepared by spin coating
}

\author{
Shota Inudo, Masao Miyake, and Tetsuji Hirato*, \\ Graduate School of Energy Science, Kyoto University, Yoshida-honmachi, Sakyo-ku, Kyoto 606-8501, Japan
}

Received ZZZ, revised ZZZ, accepted ZZZ

Published online ZZZ (Dates will be provided by the publisher.)

Keywords conductivity, carrier concentration, mobility, cuprous iodide

* Corresponding author: e-mail hirato.tetsuji.2n@kyoto-u.ac.jp, Phone: +81 75753 5432, Fax: +81 757535453

\begin{abstract}
Thin films of cuprous iodide (CuI), which is expected to be used in solid-state dye-sensitized solar cells as a hole conductor, were formed by spin coating and subsequent annealing. The effects of the annealing conditions on the electrical properties of the CuI films were investigated by resistivity and Hall-effect measurements. The CuI films showed p-type conduction with resistivities of $0.3-5 \Omega$ $\mathrm{cm}$, carrier concentrations of $1 \times 10^{18}-1 \times 10^{19} \mathrm{~cm}^{-3}$ and
\end{abstract}

mobilities of $0.5-2 \mathrm{~cm}^{2} \mathrm{~V}^{-1} \mathrm{~s}^{-1}$. It was found that the resistivities of the films annealed in air were slightly lower than those annealed in an Ar atmosphere because the carrier concentrations were higher in the former than in the latter. An increase in the mobility with the rise of annealing temperature was observed in the films annealed in Ar. However, annealing in air at high temperatures oxidized $\mathrm{CuI}$ to $\mathrm{CuO}$.
1 Introduction Cuprous iodide (CuI), a p-type semiconductor with a wide band gap of $3.1 \mathrm{eV}$, has received much attention in recent years as a hole conductor of fully solid-state dye-sensitized solar cells [1-10]. Conventional dye-sensitized solar cells consist of nanoporous $\mathrm{TiO}_{2}$, dye, and a liquid electrolyte containing the iodide/tri-iodide redox couple. The use of the liquid electrolyte, however, causes problems such as electrode corrosion and electrolyte leakage from incomplete sealing $[10,11]$. These problems can be solved by replacing the liquid electrolyte with a solid p-type semiconductor as the hole conductor [10, 11]. Solid-state dye-sensitized solar cells using $\mathrm{CuI}$ as the hole conductor have been reported to show power conversion efficiencies of 2.8-6.0\% [1-6, 10]. In these reports, the CuI layers were deposited by drop coating $[1-3,10]$, pulsed laser deposition [4, 5, 12], and electrodeposition [6, 13]. Other methods used for the preparation of $\mathrm{CuI}$ thin films have also been reported, including vacuum evaporation [14, 15], spin coating [16], and sputtering [17].

The electrical properties of the hole-conducting layer such as carrier concentration and mobility can greatly affect the performance of the solid-state dye-sensitized solar cells, and knowledge of these properties is thus of great importance. A bulk CuI single crystal prepared by the hydrothermal method was shown to have a resistivity, carrier concentration, and mobility of $3.2 \Omega \mathrm{cm}, 4.3 \times 10^{16} \mathrm{~cm}^{-3}$, and $43.9 \mathrm{~cm}^{2} \mathrm{~V}^{-1} \mathrm{~s}^{-1}$, respectively [18]. As for CuI thin films, resistivities in the range of $10^{-2}-10^{3} \Omega \mathrm{cm}[12,15-$ 17], depending on process conditions, were reported. Little is known about the carrier concentration and mobility of the CuI films, however. Although Kokubun et al. reported that $\mathrm{CuI}$ films prepared by vacuum evaporation had a carrier concentration of $1 \times 10^{17}-2 \times 10^{18} \mathrm{~cm}^{-3}$ and a mobility of $\sim 10 \mathrm{~cm}^{2} \mathrm{~V}^{-1} \mathrm{~s}^{-1}$ [14], the values for CuI films prepared by other methods are unknown.

In this study, we investigated the electrical properties of $\mathrm{CuI}$ thin films prepared by spin coating of a precursor solution and subsequent annealing. The annealing was performed at various temperatures in air and in an Ar atmosphere, and the carrier concentration and mobility of the resulting CuI films were determined by resistivity and Halleffect measurements. The effects of the annealing conditions on the electrical properties of the CuI thin films were examined.

2 Experimental procedure $\mathrm{CuI}$ thin films were formed by spin coating a precursor solution on glass substrates, followed by annealing. The substrates $(13 \times 13$ $\mathrm{mm}$ ) were cleaned in distilled water containing a detergent, acetone $(99.0 \%$ purity, Wako Pure Chemical Industries, Ltd.), and 2-propanol (99.7\% purity, Wako Pure Chemical 
Industries, Ltd.) using a sonicator for 15 min each. The precursor solution was prepared by mixing 2-aminoethanol (99.0\% purity, Wako Pure Chemical Industries, Ltd.), 2metoxyethanol (99.0\% purity, Wako Pure Chemical Industries, Ltd.), and CuI powder (95.0\% purity, Wako Pure Chemical Industries, Ltd.) according to the molar ratio of 10:10:4. The spin coating was performed at $4000 \mathrm{rpm}$ for 1 min. The spun films were annealed in air or in an Ar atmosphere at $110-350^{\circ} \mathrm{C}$ for $1 \mathrm{~h}$.

$\mathrm{X}$-ray diffraction (XRD) measurements using the $\theta-2 \theta$ scan mode were carried out to identify the phase of the CuI films. A scanning electron microscope (SEM; Hitachi, X900) was used to observe the microstructures of the films.

The electrical resistivity and Hall effect were measured at room temperature with a resistivity and Hall measurement system (Toyo Technica, Resi Test 8300) employing the van der Pauw method. Four Pt-Pd alloy electrodes measuring $1 \mathrm{~mm}$ in diameter were sputtered on each corner of the films to provide the ohmic contacts. The AC magnetic field method was used for the measurement to obtain a Hall voltage with a high signal-to-noise ratio. In this measurement, the magnitude and polarity of the magnetic field, which was applied perpendicular to the surface of the films, were alternated periodically, while a direct current was passed across the films using one diagonal pair of the four Pt-Pd alloy electrodes connected to a current source. The alternating Hall voltage induced synchronously with the AC magnetic field was then detected using the other pair of electrodes with a frequency response analyzer. The magnitude and frequency of the magnetic field were $0.32 \mathrm{~T}$ and $200 \mathrm{mHz}$, respectively. The Hall voltage measurement was repeated for the reversed current flow as well as for switched electrode pairs employed for the current flow and measuring the voltage, and the four measured values of resulting Hall voltage were averaged. The measurement was validated by confirming that the Hall voltages obtained were proportionate with the various applied currents in the range of 50-500 $\mu \mathrm{A}$. The concentration and mobility of the major carrier were calculated from the Hall voltage and the thickness of the $\mathrm{CuI}$ film determined by cross-sectional SEM observation.

\section{Results and discussion}

3.1 Preparation of Cul films CuI films were formed on a glass substrate by spin coating of the precursor solution, which was a mixture of CuI, 2-aminoethanol, and 2-metoxyethanol, followed by annealing in air. The XRD patterns of the spin-coated films before and after the annealing are shown in Fig. 1. The diffraction peaks of the film before annealing (Fig. 1a) could not be assigned to any specific compounds reported in literatures, although it must consist of copper, iodine and organic constituents. After the annealing process at $100^{\circ} \mathrm{C}$, the intensity of the peaks from the precursor decreased, but diffraction from $\mathrm{CuI}$ was not detected at this temperature (Fig. 1b). The patterns of the films annealed at $110-250^{\circ} \mathrm{C}$ (Figs. 1c and d) corresponded to that of $\mathrm{CuI}$, showing that the organic con- stituents in the precursor evaporated and $\mathrm{CuI}$ formed at temperatures above $110^{\circ} \mathrm{C}$. Although no diffraction peaks other than those of $\mathrm{CuI}$ appeared in the pattern of the films annealed in the temperature range at $110-200^{\circ} \mathrm{C}$, a closer look at the pattern of the film annealed at $250^{\circ} \mathrm{C}$ revealed

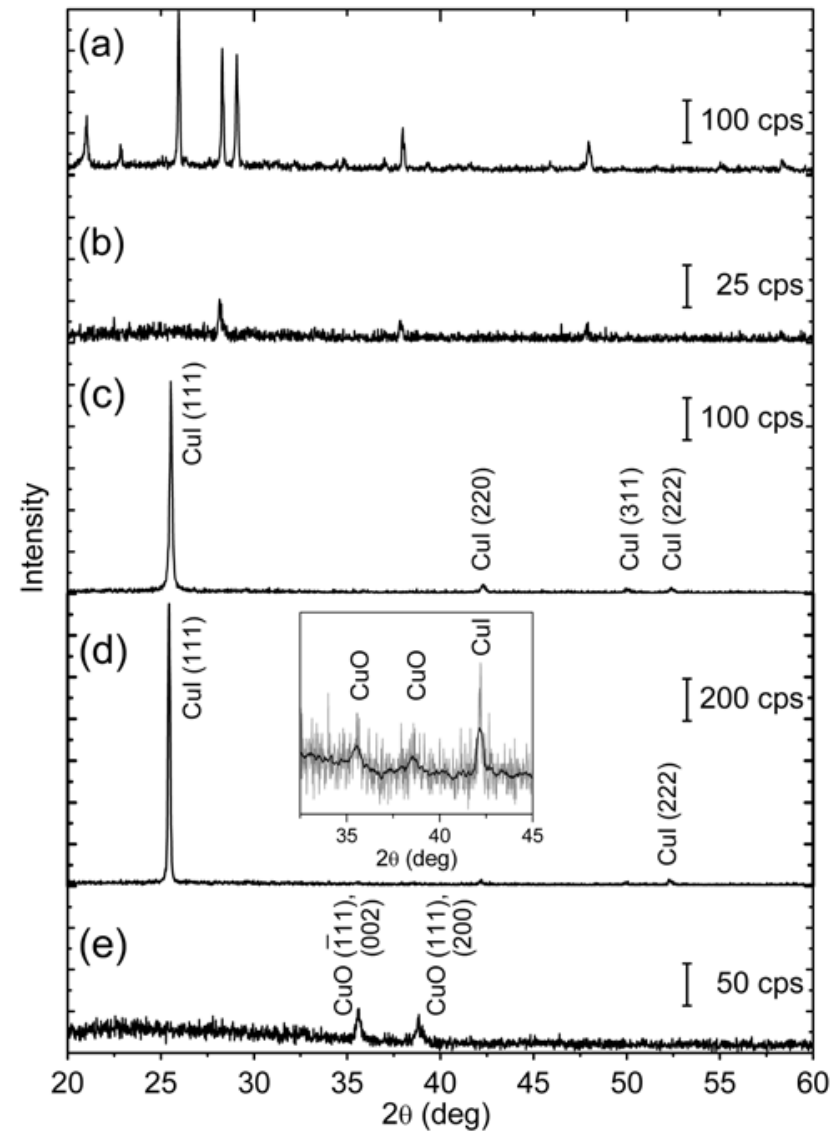

Figure 1 XRD patterns of the spin-coated films (a) before and after annealing in air at (b) $100^{\circ} \mathrm{C}$, (c) $110^{\circ} \mathrm{C}$, (d) $250^{\circ} \mathrm{C}$, and (e) $350^{\circ} \mathrm{C}$.

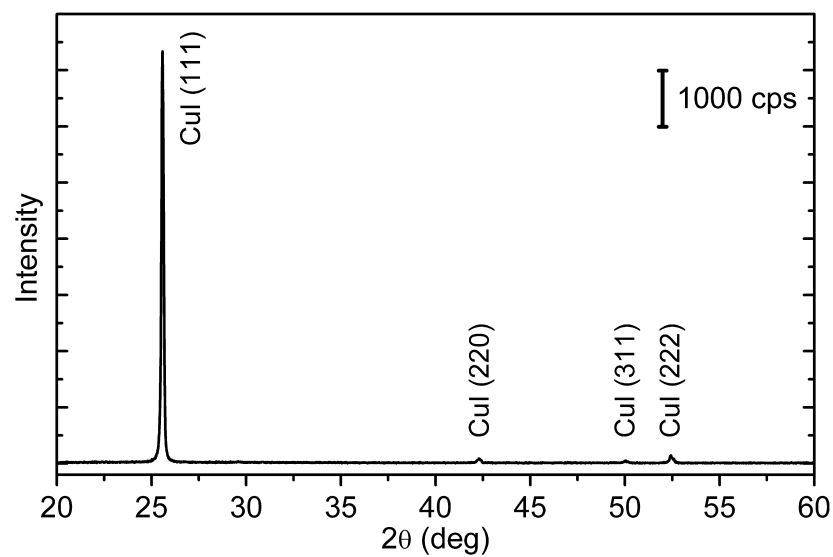

Figure 2 XRD pattern of the film annealed in an Ar atmosphere at $340^{\circ} \mathrm{C}$

small peaks corresponding to $\mathrm{CuO}$ in the $2 \theta$ range of $35-$ 
$40^{\circ}$ (inset of Fig. 1d), indicating that the oxidation of $\mathrm{CuI}$ began at $250^{\circ} \mathrm{C}$. The pattern of the film at $350^{\circ} \mathrm{C}$ (Fig. 1e) was in agreement with that of $\mathrm{CuO}$, showing that the film was completely oxidized to $\mathrm{CuO}$.

In order to prevent the $\mathrm{CuI}$ film from oxidizing to $\mathrm{CuO}$, the annealing of the films was also performed in an Ar atmosphere. The XRD pattern of the film annealed in $\mathrm{Ar}$ at $340^{\circ} \mathrm{C}$ (Fig. 2) showed only the peaks corresponding to $\mathrm{CuI}$ and no peaks of $\mathrm{CuO}$ were detected, confirming that the film annealed in Ar was not oxidized even at an annealing temperature above $250^{\circ} \mathrm{C}$. As the annealing temperature increased, a significant increase in the intensity of the CuI (111) reflection was observed, indicating an improvement in the crystallinity of CuI. In every XRD pattern of the CuI films, the intensity of the (111) reflection was much higher than those of the other peaks, showing that the $\mathrm{CuI}$ films had a strong $<111>$ texture. The lowest surface energy of the $\{111\}$ plane of a CuI crystal, which has a zinc blende structure, is believed to lead the growth of the $<111>$ texture $[12,13]$, although the detailed mechanism is not clear.

Typical SEM images of the CuI films are shown in Fig. 3. Dendritic grains with dimensions of $4-10 \mu \mathrm{m}$, consisting of primary grains with the dimensions of $0.5-1 \mu \mathrm{m}$ were observed on the surface (Fig. 3a). The cross-sectional image shows that the thickness of the CuI film was 0.78-0.85 $\mu \mathrm{m}$ (Fig. 3b).
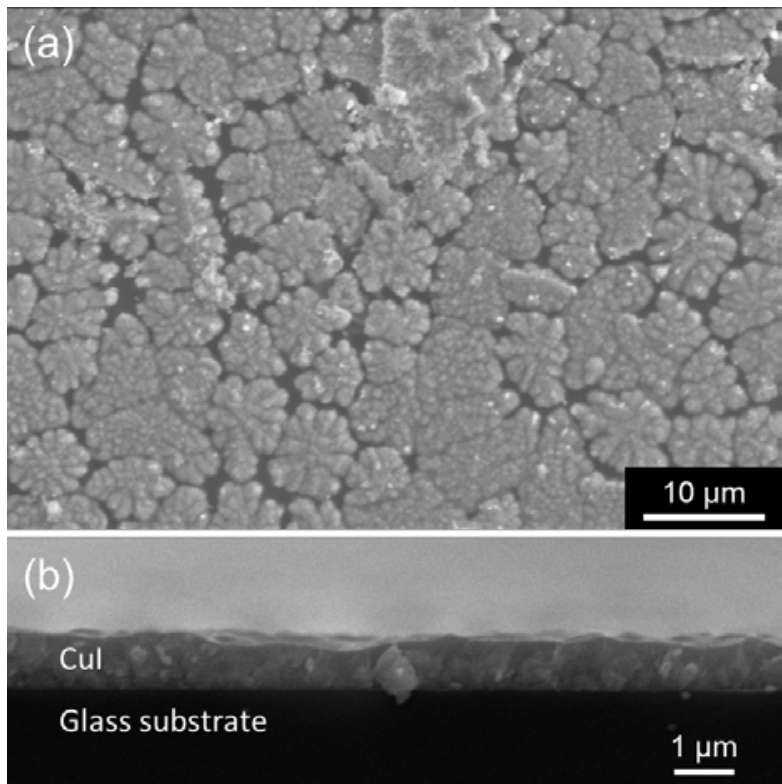

Figure 3 Typical SEM images of the (a) surface and (b) fractured cross-section of $\mathrm{CuI}$ films annealed in an Ar atmosphere.

3.2 Electrical properties The electrical properties of the CuI films were investigated by resistivity and Halleffect measurements employing the van der Pauw method (Fig. 4). The resistivities of the CuI films annealed in an $\mathrm{Ar}$ atmosphere were in the range of $1-5 \Omega \mathrm{cm}$. The films an-

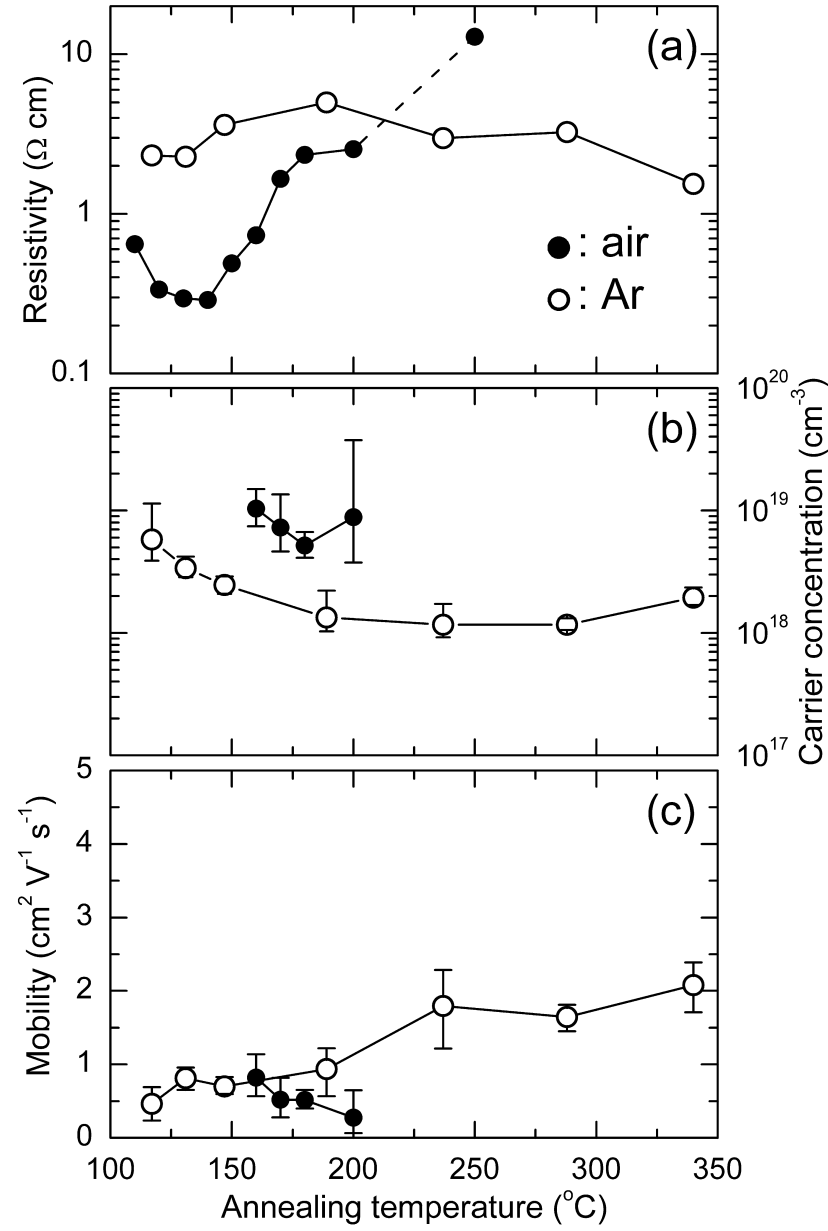

Figure 4 (a) Resistivity, (b) carrier concentration, and (c) mobility of CuI films annealed at various temperatures in air and in Ar.

nealed in air at temperatures below $200^{\circ} \mathrm{C}$ exhibited slightly lower resistivities compared with those annealed in $\mathrm{Ar}$ at the same temperature. The lowest resistivity $(0.3 \Omega \mathrm{cm})$ was obtained at an annealing temperature of around $130^{\circ} \mathrm{C}$. However, the resistivities of the films annealed in air tended to increase with increasing annealing temperature, and they became too high to be measured at temperatures above $250^{\circ} \mathrm{C}$. This significant increase in the resistivity should have been caused by the oxidation of $\mathrm{CuI}$ to form CuO.

The Hall-effect measurements confirmed that all the $\mathrm{CuI}$ films that were annealed in Ar had p-type conduction. While the films annealed in air in the temperature range of $160-200^{\circ} \mathrm{C}$ were confirmed to have p-type conduction, it was not possible to determine the conduction type of the films annealed at temperatures outside that range, because Hall voltages with a high signal-to-noise ratio could not be obtained from these films. This result implies that the carrier mobilities were quite small in these films.

As shown in Fig. 4b, the carrier concentrations of the CuI films determined from the Hall-effect measurements were in the range of $1 \times 10^{18}-1 \times 10^{19} \mathrm{~cm}^{-3}$. The carrier 
concentrations were slightly higher in the films annealed in air than in the films annealed in Ar, leading to the lower resistivities of the films annealed in air. It has been reported that $\mathrm{Cu}$ vacancy $\left(\mathrm{V}_{\mathrm{Cu}}\right)$ in $\mathrm{CuI}$ plays the role of the dominant native acceptor, and oxygen in CuI generates an additional acceptor level $[14,15,19]$. The tendency for the carrier concentrations observed in the films annealed in Ar to decrease with increasing annealing temperature was attributable to a decrease in the concentration of $\mathrm{V}_{\mathrm{Cu}}$. As can be inferred from the low boiling point of elemental iodine $\left(184.3^{\circ} \mathrm{C}\right)$, the vapor pressure of iodine in $\mathrm{CuI}$ should be relatively high [14], and thus the evaporation of a trace amount of iodine from a CuI film appeared to have occurred during the annealing stage, which decreased the concentration of $\mathrm{V}_{\mathrm{Cu}}$, and the hole concentration decreased accordingly. Annealing the CuI films in air should have introduced oxygen into the films, leading to higher carrier concentrations.

The carrier mobilities in the CuI films annealed in $\mathrm{Ar}$ were in the range of $0.5-2 \mathrm{~cm}^{2} \mathrm{~V}^{-1} \mathrm{~s}^{-1}$, and the values increased slightly with the rise of the annealing temperature (Fig. 4c). The increase in mobility should have been caused by the reduction of carrier scattering through the improvement of CuI crystallinity. On the other hand, the mobilities in the films annealed in air tended to decrease as the annealing temperature increased. This decrease in mobility must have been caused by the oxidation of the films.

The carrier concentrations and mobilities were comparable to values reported for $\mathrm{CuI}$ films prepared by vacuum evaporation [14], although there were small differences where the carrier concentrations and mobilities were slightly higher and lower, respectively, in the films obtained in this study. A possible cause of these differences was the incorporation of impurities originating from the organic constituents of the precursor solution.

4 Conclusion CuI films were prepared by spin coating of a precursor solution and subsequent annealing at different temperatures in air and in an $\mathrm{Ar}$ atmosphere. The annealing process in air yielded CuI films in the temperature range of $110-200^{\circ} \mathrm{C}$, whereas oxidation of $\mathrm{CuI}$ to $\mathrm{CuO}$ occurred at higher temperatures. The annealing process in an $\mathrm{Ar}$ atmosphere formed $\mathrm{CuI}$ films without oxidation even at temperatures above $250^{\circ} \mathrm{C}$. The CuI films exhibited ptype conduction with resistivities of $0.3-5 \Omega \mathrm{cm}$, hole concentrations of $1 \times 10^{18}-1 \times 10^{19} \mathrm{~cm}^{-3}$ and mobilities of 0.5 $2 \mathrm{~cm}^{2} \mathrm{~V}^{-1} \mathrm{~s}^{-1}$. Compared with the films annealed at the same temperature in Ar, the films annealed in air had slightly higher hole concentrations. An increase in the mobility in the films annealed in Ar with increasing annealing temperature was observed.

\section{References}

[1] H. Sakamoto, S. Igarashi, K. Niume, M. Nagai, Organic Electronics 12, 1247 (2011).
[2] S. Moribe, A. Takeichi, J. Seki, N. Kato, K. Higuchi, K. Ueyama, K. Mizumoto, T. Toyoda, Applied Physics Express 5, (2012).

[3] G.R.A. Kumara, S. Kaneko, M. Okuya, K. Tennakone, Langmuir 18, 10493 (2002).

[4] M. Rusop, International Conference on Nanoscience and Nanotechnology (NANO-SciTech 2008), Selangor, Malaysia, 2008, p. 861-866.

[5] M. Rusop, T. Soga, T. Jimbo, M. Umeno, Surface Review and Letters 11, 577 (2004).

[6] E.V.A. Premalal, R.M.G. Rajapakse, A. Konno, Electrochimica Acta 56, 9180 (2011).

[7] K. Tennakone, G. Kumara, A.R. Kumarasinghe, K.G.U Wijayantha, P.M. Sirimanne, Semiconductor Science and Technology 10, 1689 (1995).

[8] V.P.S. Perera, K. Tennakone, Solar Energy Materials and Solar Cells 79, 249 (2003).

[9] M.N. Amalina, N.A. Rasheid, M. Rusop, Journal of Nanomaterials (2012).

[10] L. Yang, Z.X. Zhang, S.H. Fang, X.H. Gao, M. Obata, Solar Energy 81, 717 (2007).

[11] S. Tanaka, Japanese Journal of Applied Physics Part 1Regular Papers Short Notes \& Review Papers 40, 97 (2001)

[12] B.L. Zhu, X.Z. Zhao, Phys Status Solidi A 208, 91 (2011).

[13] H.L. Kang, R. Liu, K.L. Chen, Y.F. Zheng, Z.D. Xu, Electrochimica Acta 55, 8121 (2010).

[14] Y. Kokubun, H. Watanabe, M. Wada, Japanese Journal of Applied Physics 10, 864 (1971).

[15] C.S. Herrick, A.D. Tevebaugh, Journal of the Electrochemical Society 110, 119 (1963).

[16] A.M. Nur, A.A. Muhammad, M.R. Mahmood, Nanomaterials: Synthesis and Characterization 364, 417 (2012).

[17] T. Tanaka, K. Kawabata, M. Hirose, Thin Solid Films 282, 179 (1996).

[18] D.G. Chen, Y.J. Wang, Z. Lin, J.K. Huang, X.Z. Chen, D.M. Pan, F. Huang, Crystal Growth \& Design 10, 2057 (2010).

[19] K. Tennakone, G. Kumara, I.R.M. Kottegoda, V.P.S. Perera, G. Aponsu, K.G.U. Wijayantha, Sol Energ Mat Sol C 55, 283 (1998). 